\title{
Sensitive Periods of Moving on Mental Health and Academic Performance Among University Students
}

\author{
Ming $\mathrm{Li}^{1+}$, Wen-Qiao $\mathrm{Li}^{2+}$ and Liman Man Wai Li3* \\ ${ }^{1}$ Centre for Mental Health, Jishou University, Jishou, China, ${ }^{2}$ Department of Behavioral Science, Hokkaido University, \\ Sapporo, Japan, ${ }^{3}$ Department of Psychology and Centre for Psychosocial Health. The Education University of Hong Kong, \\ Tai Po, Hong Kong
}

Moving within and across nations becomes a non-reversible increasing trend globally. The current research investigated the unique effect of residential mobility at different developmental stages (i.e., early childhood, late childhood, and adolescence) on university students' mental health and academic performance. In addition, we investigated the role of two different types of coping resources, i.e., resilience and family income, in moderating the negative effect of residential mobility. The data from

OPEN ACCESS

Edited by:

Monica Pellerone,

Kore University of Enna, Italy

Reviewed by:

Daniel Tan Lei Shek,

Hong Kong Polytechnic University,

Hong Kong

Jesús Nicasio García Sánchez,

Universidad de León, Spain

*Correspondence:

Liman Man Wai L

mwli@eduhk.hk;

liman.Imw@gmail.com

†These authors have contributed equally to this work

Specialty section:

This article was submitted to Educational Psychology, a section of the journal

Frontiers in Psychology

Received: 15 January 2019 Accepted: 16 May 2019

Published: 13 June 2019

Citation:

Li M, Li W-Q and Li LMW (2019) Sensitive Periods of Moving on

Mental Health and Academic

Performance Among University

Students. Front. Psychol. 10:1289.

doi: 10.3389/fpsyg.2019.01289
3753 first-year university students revealed that: (1) residential mobility in late childhood and adolescence (but not in early childhood) predicted poorer mental health among university students; (2) high resilience and higher family income alleviated the association of residential mobility in adolescence and mental health status; and (3) residential mobility in adolescence (but not in early childhood and late childhood) was associated with poorer academic performance but this pattern was not moderated by resilience or family income. The theoretical implications and practical implications of these findings were discussed.

Keywords: residential mobility, mental health, resilience, income, academic performance, sensitive periods

\section{INTRODUCTION}

In recent years, high residential mobility within and across nations has gradually become an inevitable part in the contemporary world (Baldassare et al., 1979; Hilton and van Minnen, 2002; Ruback et al., 2004; Oishi et al., 2009). Researchers have been trying to uncover the effect of residential mobility on people's lives across multiple domains, including attachment to community (Sampson, 1988), prosocial behaviors (Oishi et al., 2007b; Lun et al., 2012; Li et al., 2019, Li et al., unpublished), social relationships (e.g., Oishi et al., 2013; Li, 2017), and self-identity (Oishi, 2010). Among different domains, the research line that explores the influence of residential mobility on adjustment has been receiving a lot of attention. Specifically, whether residential mobility would have positive or negative consequences upon people's mental health (Kessler and Magee, 1993; DeWit, 1998; Oishi and Graham, 2010; Boynton-Jarrett et al., 2013) is the key research question. In general, it was found that residential mobility has detrimental effects on people's mental health (Kessler and Magee, 1993; DeWit, 1998; Oishi and Graham, 2010). For instance, prior work found that residential mobility in childhood was associated with an increased risk of developing a wide range of psychiatric disorders, including behavior-related disorders (e.g., suicidal behavior) and antisocial personality disorder, 
on reaching maturity (Jelleyman and Spencer, 2008; Green et al., 2010; Kessler et al., 2010; Brown et al., 2012; Boynton-Jarrett et al., 2013; Mok et al., 2016; Tseliou et al., 2016).

There were some limitations in previous studies. First, they mostly investigated the relationship between residential mobility and mental health without pinpointing the unique effect of residential mobility at different developmental stages. In other words, they ignored the possibility that moving experience may bring greater challenges at a specific developmental stage than in other development stages as suggested by some developmental theories (Erikson, 1963; Lin, 1983). In addition, mental health was primarily examined, thus it remains unknown whether the effect of residential mobility would extend to other aspects of functioning.

To address these concerns, the current research simultaneously examined the effect of residential mobility at different developmental stages, including early childhood (before age 6), late childhood (age 6-12), and adolescence (age 12-18), on university students' mental health as well as their academic performance, an extensively used objective indicator of functioning at school (Glew et al., 2005; Keogh et al., 2006; Ramos-Sánchez and Nichols, 2007). Furthermore, we explored whether two types of coping resources, i.e., resilience (psychological capital) and family income (physical capital), would independently, or interactively play a moderating role in the effect of residential mobility on these two functioning aspects.

\section{Residential Mobility, Mental Health, and Academic Performance}

A lot of theories contend a close relation between early experiences and current psychological experiences and outcomes. According to the classical Freud's (1940) theory, people's core personality traits are highly affected by the experience in childhood. Specifically, it highly depends on whether people have learned how to regulate and satisfy their desires in early developmental stages. The conditions, including fewer economic resources and higher level of residential mobility (Albrecht and Teachman, 2003; McGloin and Thomas, 2016) in childhood, are likely to undermine self-regulation, which can result in increased risks for mental health problems, and poor behavior outcomes during later developmental stages. This notion is in line with some empirical evidence showing that residential mobility impaired people's self-control (Zhou et al., unpublished). In addition, based on the attachment theory, residential mobility, which causes disruption of peer relationship in childhood, is likely to link to interpersonal insecurity at later developmental stages (Bucci et al., 2015; Widom et al., 2018), which is a significant predictor of poor mental health and poor academic performance (Cordes et al., 2016; Langenkamp, 2016; Voight et al., 2017). Supporting the theories discussed above, empirical evidence exists in supporting the relation between residential mobility and mental health, and the relation between residential mobility and academic performance, which is outlined below.

\section{Residential Mobility and Mental Health}

Mental health is a significant determinant of individuals' growth and well-being in the whole life span (Power and Hertzman, 1997;
Bures, 2003; Ruddy et al., 2005; Jelleyman and Spencer, 2008; Oishi and Schimmack, 2010; Shiraga et al., 2013). Previous work shows that residential mobility has significant impacts on individuals' mental health (Kessler and Magee, 1993; DeWit, 1998; Oishi and Graham, 2010), associating with more mental health problems (e.g., depression, schizophrenia, and anxiety) (Tunstall et al., 2014a,b). In general, frequent moving induces a series of stressors (e.g., family stress and household chaos), which can cumulate to bring detrimental impacts on mental health (Leventhal and Newman, 2010; Boynton-Jarrett et al., 2013).

\section{Residential Mobility and Academic Performance}

Some research has directly tested the relation between residential mobility and academic performance (e.g., Herbers et al., 2012; Voight et al., 2012; Schmitt et al., 2015), showing that moving experiences led to poorer academic performance among children, and adolescents (Herbers et al., 2012; Voight et al., 2012; Schmitt et al., 2015).

However, as stated previously, previous studies mostly tested the influence of total number of moving experiences and the short-term effect of residential mobility. It remains unclear whether the effect of residential mobility at different developmental stages would predict people's mental health and academic performance in later developmental stages.

\section{The Effect of Residential Mobility in Different Developmental Stages}

Individuals have different needs and developmental tasks to fulfill in each developmental stage (Erikson, 1963; Lin, 1983), suggesting that moving at certain developmental stages may bring greater challenges during the processes of achieving specific developmental tasks and goals. Thus it would be possible that residential mobility at different developmental stages would exert unique effect in different domains. To test this possibility, we followed the theory in the research of developmental psychology (Lin, 1983) to focus on three developmental stages: (a) early childhood - age before 6; (b) late childhood - age 6-12; (c) adolescence (age 12-18).

\section{Sensitive Period of Moving on Mental Health}

According to the personality development theory of Erikson (Erikson, 1963), individuals have to fulfill distinctive needs and developmental tasks to achieve better mental health in each developmental stage. Accumulated evidence converges to demonstrate that one of the most notable domains affected by residential mobility is social relationship (e.g., Sampson, 1988; Magdol and Bessel, 2003; Adam, 2004; Shklovski, 2007; Oishi, 2010; Sharkey and Sampson, 2010). Moving leads to destruction of one's established social networks, which is a strong determinant of poor mental health (Greenblatt et al., 1982; Kawachi and Berkman, 2001). Therefore, changes in social relationships associated with residential mobility may be more detrimental to mental health in the developmental stage where the developmental task is highly related to social relationship.

Before age 6 (in early childhood), children mostly rely on their caregivers to overcome obstacles and develop a sense of security, therefore the quality of the relationship with the caregivers is 
the most important factor for their mental health (Lin, 1983), exerting short-term, and long-term influences (Bakeman and Brown, 1980; Crittenden, 1992; Mickelson et al., 1997). In contrast, previous research showed that children younger than age 6 were unlikely to have enduring peer relationships and group memberships (Ladd and Troop-Gordon, 2003). Thus, unless moving causes a separation with the caregivers, changes in social relationships caused by residential mobility at this stage were expected to have a minimal impact on mental health.

Since age 6 (in late childhood and adolescence), people begin to receive education with other people, which makes peer relationship to be a dominant factor of people's psychological growth in this developmental stage (Armsden and Greenberg, 1987; Repper and Carter, 2011). As a result, people in late childhood and adolescence would become sensitive to changes in the living environments that could potentially affect their peer relationships (Hardy et al., 2002). Research on residential mobility consistently revealed that residential moves destroy extant social ties (Oishi, 2010; Oishi et al., 2013), thus it could be very challenging for people moving in late childhood or adolescence to maintain good relationships with their peers, which would in turn lead to poorer mental health. Moreover, the impacts upon peer relationships induced by residential mobility may serve to initiate mental health trajectories that can have a lasting effect on individuals, increasing their mental health vulnerabilities in later lives (Wadsworth, 1997).

Taken together, we expected that residential mobility after early childhood would have more notable detrimental effects on people's mental health in later lives, whereas the effect of moving in early childhood on mental health would be rather minimal.

\section{Sensitive Period of Moving on Academic Performance}

As discussed previously, the personality development theory of Erikson (Erikson, 1963) proposed that the major developmental tasks for people in early and late childhood are to establish a secure relationship with their caregivers and peers, respectively. In contrast, the major developmental task in adolescence is related to "the self" (Erikson, 1963; Lin, 1983). That is to develop one's self-identity through exploring the experience, need, emotion, ability, and goals that are related to "the self" (Kroger, 1989; Campbell and Lavallee, 1993). One way to develop one's self-identity is through proving one's ability. Therefore, selfidentity achievement, which is crucial during adolescence, was found to be positively associated with academic performance (Sherman et al., 2013; Jelenic, 2014). Furthermore, the association between self-identity achievement and academic performance was also found among university students (Berzonsky and Kuk, 2005), indicating that the development of self-identity may have a long-term effect on academic performance.

Erikson (1968) proposed that sensing the change and deprivation of one's environment is very likely to lead to role confusion among adolescents, leading to failure of accomplishing self-identity achievement. Hence, the changes in physical and social environments associated with residential mobility may be more detrimental to people's academic performance when they move in adolescence. Inevitably, moving creates a lot of stressful situations, which causes tremendous pressure, and anxiety for individuals (Leventhal and Newman, 2010; Boynton-Jarrett et al., 2013; Tunstall et al., 2014a,b) and in turn, results in reduced selfcontrol and delayed gratification (Oishi and Talhelm, 2012; Zhou et al., unpublished). These experiences associated with moving are likely to shape self-identity processes (Oishi, 2010; Eggleston and Oishi, 2013) that are more crucial in adolescence, which may in turn affect academic performance more notably (Culler and Holahan, 1980; Seipp, 1991; Bembenutty, 1999; Cassady and Johnson, 2002; Duckworth and Seligman, 2005; Hagger et al., 2010). Consistent with this notion, residential mobility was found to be correlated with poor identity achievement of adolescence (Oishi, 2010; Eggleston and Oishi, 2013) and in turn associated with poorer academic performance (Voight et al., 2012). Moreover, based on previous findings that self-identity development has long-term impacts on academic performance (Berzonsky and Kuk, 2005), the influence of moving experiences in adolescence on academic performance is likely to be extended to the university setting.

Therefore, we expected that moving frequency in adolescence would have a notable detrimental effect on academic performance among university students whereas the influence of moving frequency in early and late childhood would be minimal.

\section{The Moderating Role of Coping Resources}

Some factors, including motivation of moving, the amount of time involved in moving (Scanlon and Devine, 2001), social support from significant others (Hendershott, 1989), and familial stability (Gilman et al., 2003), are identified to significantly moderate the outcomes of moving. To further examine the effect of residential mobility at different developmental stages on mental health and academic performance among university students, we also examined the moderating role of two types of coping resources: individuals' resilience and their family income.

\section{The Moderating Role of Resilience}

Little research explored the moderating role of individual characteristics. In the present research, we tested the role of resilience, an important personality factor that predicts adjustments in a wide range of stressful situations (e.g., Rutter, 1985; Dumont and Provost, 1999; Bonanno, 2004; Campbell-Sills et al., 2006; Giallo and Gavidia-Payne, 2006; Troy and Mauss, 2011), on alleviating the impact of residential mobility. Resilience refers to the ability to recover from stress (Masten, 2007). People with higher resilience can adapt to stressful circumstances (Carver, 1998; Tusaie and Dyer, 2004). In general, people high in resilience tend to perceive more positive emotions and social support, which help to buffer stress (Tugade and Fredrickson, 2004; Friborg et al., 2005). In addition to its direct influence on adaptation, resilience can also alleviate the negative impact of some factors during adaptation. For instance, resilience reduced the incidence of schizophrenia in harsh living environments (Anthony, 1974).

Based on these findings, we speculated that high resilience would be likely to weaken the negative association between residential mobility and adjustment outcomes among university 
students. Specifically, we hypothesized that the influence of residential mobility in late childhood and adolescence on poorer mental health would be weaker among the university students with higher resilience. Similarly, we expected that the influence of residential mobility in adolescence on academic performance would be weaker among the university students with higher resilience.

\section{The Moderating Role of Family Income}

Another examined moderator is family income. Some previous studies suggested that the close association between exposure to childhood residential mobility and subsequent adverse outcomes could be restricted to households with lower family income, where a lot of psychosocial difficulties emerge (Webb et al., 2016). First, a weaker relation between residential mobility and adverse outcomes in households with higher family income may reflect aspirational residential movements for better employment, housing, and educational opportunities (Webb et al., 2016; Basolo and Yerena, 2017). In addition, family poverty has been identified to be a risk factor for a wide range of mental health and behavior issues among the youth (Letourneau et al., 2013; Reiss, 2013; Coley et al., 2018). In families with fewer economic resources, parents may not be able to provide sufficient emotional support to their children to cope with different challenges (Albrecht and Teachman, 2003), such as moving, which may eventually link to an increased risk for poor mental health and poor academic performance (Basolo and Yerena, 2017; Mollborn et al., 2018).

Based on previous findings, we expected that high family income would weaken the negative association between residential mobility and adjustment outcomes among university students. Specifically, we hypothesized that the influence of residential mobility in late childhood and adolescence on poorer mental health would be weaker among the university students with higher family income. Similarly, we expected that the influence of residential mobility in adolescence on academic performance would be weaker among the university students with higher family income.

\section{Overview of the Research}

The primary aim of the current research was to investigate the unique effects of residential mobility at different developmental stages on different aspects of functioning in later lives. We recruited first-year students from a university in China to investigate how residential mobility at the three different developmental stages would affect university students' mental health and academic performance. We hypothesized that: (a) residential mobility in late childhood and adolescence (but not early childhood) would predict poorer mental health among university students; (b) residential mobility in adolescence (but not in early childhood and late childhood) would predict poorer academic performance; and (c) higher resilience and higher family income would weaken the association of residential mobility with poor mental health and with poor academic performance. In addition, we explored whether resilience and family income would independently or interactively moderate the outcomes associated with residential mobility. Because both resilience and family income are important coping resources, we speculated that high resilience and high family income may jointly exert a stronger moderating effect.

\section{MATERIALS AND METHODS}

\section{Participants}

Participants were 3753 first-year students (1436 male participants, 2317 female participants; $\left.M_{\text {age }}=18.65, S D=3.05\right)$ from a university in mid-West of China. Participants were majoring in a wide range of disciplines, including arts (53.2\%), science $(26.2 \%)$ and engineering $(20.7 \%)$. There were 2611 Han Chinese participants, and 1142 participants with ethnic minority background, including Tujia Chinese (23.5\%) and Miao Chinese (17.4\%). All participants voluntarily participated in the current study, and they all gave their written informed consent before taking part in the study.

\section{Procedure and Measures}

Participants completed the study through an online survey platform, i.e., Qualtrics. Using an online survey can protect participants' privacy and make sure the test is done in a private setting with as little interference as possible from others. The following measures were used to test our research questions.

\section{Residential Mobility}

Modifying the items used in Oishi et al. (2007a)'s work, we asked participants to indicate their moving history at three different age periods. Participants reported the number of moving before age 6 , between age 6 and 12, and after age 12 .

\section{Mental Health}

To measure mental health, we used the Symptom Checklist 90 (SCL-90) scale (Derogatis et al., 1973), which includes 10 dimensions: somatization, obsessive-compulsive, interpersonal sensitivity, depression, anxiety, hostility, photic anxiety, paranoid ideation, psychoticism, and additional items (e.g., "Having headaches"; "Crying easily"; and "Having trouble falling asleep"). Participants indicated the extent to which they were affected by each of the problems described using a 5-point Likert-scale ranging from 1 (not at all) to 5 (extremely). The score of mental health was composited by summing up the scores of all items $(\alpha=0.977$, McDonald's omega $=0.972)$, with higher scores indicating poorer mental health. This scale has been adopted in previous studies with Chinese participants (Li et al., 2016), and it was demonstrated to be reliable and valid among Chinese participants.

\section{Academic Performance}

We were able to obtain 3078 students' scores of final exams at the first semester. Academic performance was computed by averaging the participants' scores of all courses enrolled.

\section{Family Income}

Participants indicated their monthly family household income on a 7-point Likert scale, which ranged from 1 "less than 1000 RMB" to 7 "more than 5000 RMB." 


\section{Resilience}

Participants completed a resilience scale (Smith et al., 2008), which contains six items on a 5-point Likert-scale ranging from 1 (strongly disagree) to 5 (strongly agree). The sample items include, "I tend to bounce back quickly after hard times," and "I have a hard time making it through stressful events" (reverse-scored item). An average score was computed $(\alpha=0.743$, McDonald's omega $=0.730)$, with higher scores indicating higher level of resilience. Previous studies with Chinese participants have adopted this measure of resilience (Ye et al., 2017), which showed that this scale is reliable among Chinese participants.

\section{Statistical Analytic Plan}

We analyzed the data using SPSS version 25 (I.B.M Corp, 2017) (and using $\mathrm{R}$ statistical software version 3.5.2 for McDonald's omega; R Core Team, 2018). Four linear regression models were tested for each dependent variable (i.e., mental health and academic performance). All continuous variables were mean-cantered before computing interaction terms and entering into the analyses. In Model 1, in order to test the effect of residential mobility at different developmental stages, we regressed the dependent variable on residential mobility at the three developmental stages (early childhood - before age 6, late childhood - age 6-12, and adolescence - age over 12). In Model 2, we tested whether the results of Model 1 would remain similar with controlling for the effects of participants' gender and age. In Model 3, we tested whether resilience and family income would exert moderating effects independently or interactively. Specifically, the dependent variable was regressed on the effect of residential mobility at each developmental stage, the effect of resilience, the effect of family income, the interaction of resilience and residential mobility at each developmental stage, the interaction of family income and residential mobility at each developmental stage, the interaction between family income and resilience, and the 3-way interaction of resilience, family income, and residential mobility at each developmental stage. In Model 4, we added age and gender as covariates based on Model 3 and tested whether the results would remain similar.

\section{RESULTS}

\section{The Effect of Residential Mobility at Different Developmental Stages on Mental Health}

Table 1 presents the descriptive statistics of the key variables and their inter-correlations. Table 2 summarizes the results of all tested regression models. As indicated by the results of Model 1, participants' residential mobility in late childhood, $b=2.193$, $S E=1.017, t=2.157, p=0.031,95 \%$ Confidence Interval $(\mathrm{CI})$ : $[0.199,4.187]$, and that in adolescence, $b=1.954, S E=0.942$, $t=2.075, p=0.038,95 \% \mathrm{CI}$ : [0.108, 3.801], significantly predicted poorer mental health. In contrast, participants' residential mobility in early childhood did not predict mental health, $b=0.464, S E=1.029, t=0.450, p=0.652,95 \%$ CI: $[-1.554$, 2.481]. Model 2 revealed that the results remained similar with controlling for the effect of gender and age. Residential mobility in late childhood, $b=1.885, S E=1.020, t=1.847, p=0.065$, $95 \%$ CI: $[-0.116,3.886]$, and residential mobility in adolescence, $b=2.273, S E=0.942, t=2.412, p=0.016,95 \%$ CI: [0.426, 4.121 ], were still associated with poorer mental health though the effect of residential mobility in late childhood was weakened. Furthermore, residential mobility in early childhood remained non-significant in predicting mental health, $b=0.559, S E=1.031$, $t=0.542, p=0.588,95 \% \mathrm{CI}:[-1.463,2.581]$. In summary, the results indicated that residential moving experiences only after age 6 were associated with poor mental health among university students.

\section{The Moderating Role of Resilience and Family Income}

As stated in Model 3, higher level of resilience, $b=-26.292$, $S E=0.989, t=-26.579, p<0.001,95 \%$ CI: $[-28.231,-24.352]$, and higher level of family income, $b=-1.823, S E=0.364$, $t=-5.011, p<0.001,95 \% \mathrm{CI}$ : [-2.536, - 1.109], predicted better mental health. The interaction effect between resilience and family income was significant, $b=1.301, S E=0.546, t=2.381$, $p=0.017,95 \% \mathrm{CI}:[0.230,2.372]$.

Regarding the effects associated with residential mobility in early childhood, its main effect was non-significant, $b=0.588$, $S E=0.945, t=0.622, p=0.534,95 \%$ CI: $[-1.265,2.441]$. The interaction effect of resilience and residential mobility in early childhood, $b=1.486, S E=1.558, t=0.953, p=0.340$, $95 \%$ CI: $[-1.569,4.541]$, and the interaction effect of family income and residential mobility in early childhood, $b=0.012$, $S E=0.528, t=0.022, p=0.982,95 \% \mathrm{CI}:[-1.024,1.047]$, were non-significant. The 3-way interaction effect of resilience, family income, and residential mobility in early childhood was also not significant, $b=0.403, S E=0.901, t=0.447, p=0.655,95 \% \mathrm{CI}$ : $[-1.364,2.170]$.

Regarding the effects associated with residential mobility in late childhood, its main effect was marginally significant, $b=1.542, S E=0.932, t=1.654, p=0.098,95 \%$ CI: $[-0.286$, $3.370]$. The interaction effect of resilience and residential mobility in late childhood, $b=-1.901, S E=1.429, t=-1.330, p=0.183$, 95\%CI: [-4.703, 0.901], and the interaction effect of family income and residential mobility in late childhood, $b=-0.223$, $S E=0.547, t=-0.407, p=0.684,95 \% \mathrm{CI}:[-1.296,0.851]$, were not significant. The 3-way interaction effect of resilience, family income, and residential mobility in late childhood was also not significant, $b=1.101, S E=0.844, t=1.303, p=0.192,95 \% \mathrm{CI}$ : $[-0.555,2.756]$.

Regarding the effects associated with residential mobility in adolescence, its main effect was marginally significant, $b=1.532$, $S E=0.860, t=1.781, p=0.075,95 \%$ CI: $[-0.155,3.218]$. All two-way interactions associated with residential mobility in adolescence were significant: the interaction of resilience and residential mobility in adolescence: $b=-2.420, S E=1.211$, $t=-1.999, p=0.046,95 \%$ CI: $[-4.793,-0.047]$; the interaction effect of family income and residential mobility in adolescence: $b=-1.130, S E=0.482, t=-2.345, p=0.019$, 
TABLE 1 | The descriptive statistics of key variables and their inter-correlations.

\begin{tabular}{|c|c|c|c|c|c|c|c|c|}
\hline & $M$ & $S D$ & 1 & 2 & 3 & 4 & 5 & 6 \\
\hline 1. MEC & 0.370 & 0.732 & - & & & & & \\
\hline 2. MLC & 0.500 & 0.793 & $0.346 * *$ & - & & & & \\
\hline 3. MA & 0.470 & 0.800 & $0.164 * *$ & $0.382^{* *}$ & - & & & \\
\hline 4. Resilience & 3.350 & 0.658 & 0.002 & -0.022 & -0.020 & - & & \\
\hline 5. Family income & 4.400 & 1.755 & $0.037^{*}$ & $0.054^{* *}$ & $0.042^{*}$ & $0.051^{* *}$ & - & \\
\hline 6. Mental health & 159.824 & 42.541 & 0.016 & $0.049^{* *}$ & $0.053^{* *}$ & $-0.402^{* *}$ & $-0.079^{* *}$ & - \\
\hline 7. Academic performance & 79.415 & 5.558 & -0.028 & -0.025 & $-0.051^{* *}$ & -0.028 & $-0.040^{*}$ & 0.003 \\
\hline
\end{tabular}

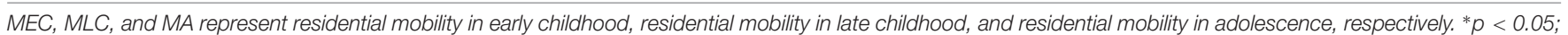
$* * p<0.01$.

95\%CI: $[-2.075,-0.185]$. Importantly, the interaction effect of resilience, family income, and residential mobility in adolescence was significant, $b=1.701, S E=0.723, t=2.353, p=0.019$, 95\%CI: [0.284, 3.119].

To unpack the 3-way interaction, simple-slope tests following the procedure suggested by Aiken and West (1991) were conducted. The results showed that residential mobility in adolescence was associated with poor mental health only when both resilience and family income were low (1SD below the mean), $b=7.073, S E=1.679, t=4.212, p<0.001,95 \% \mathrm{CI}$ : $[3.781,10.365]$; when both resilience and family were high (1SD above the mean), $b=-0.083, S E=1.600, t=-0.052, p=0.959$, 95\%CI: [-3.221, 3.055], when resilience was high but family income was low, $b=-0.003, S E=1.726, t=-0.002, p=0.999$, $95 \%$ CI: $[-3.386,3.380]$, or when resilience was low but family income was high, $b=-0.860, S E=1.670, t=0.515, p=0.607$, 95\%CI: $[-4.133,2.414]$, residential mobility in adolescence was not associated with poor mental health (see Figure 1). The results remained similar when the effect of gender and age were controlled (see Table 1, Model 4).

\section{The Effect of Residential Mobility at Different Developmental Stages on Academic Performance}

As stated in Model 1, the results showed that participants' residential mobility in adolescence, $b=-0.336, S E=0.136$, $t=-2.470, p=0.014,95 \% \mathrm{CI}$ : [-0.602, - 0.069], significantly predicted poorer academic performance. However, participants' residential mobility in early childhood, $b=-0.154, S E=0.146$, $t=-1.053, p=0.293$, 95\% CI: [ $-0.440,0133]$, and that in late childhood, $b=0.001, S E=0.144, t=0.006, p=0.996,95 \% \mathrm{CI}$ : $[-0.282,0.283]$, did not predict poorer academic performance. The results remained similar when the effect of age and gender were controlled (Model 2): residential mobility in adolescence, $b=-0.278, S E=0.130, t=-2.129, p=0.033,95 \% \mathrm{CI}:[-0.534$, $-0.022]$, residential mobility in early childhood, $b=-0.206$, $S E=0.141, t=-1.468, p=0.142,95 \% \mathrm{CI}:[-0.482,0.069]$, residential mobility in late childhood, $b=0.047, S E=0.139$, $t=0.336, p=0.737,95 \% \mathrm{CI}$ : [ $-0.226,0.319]$. In summary, the results indicated that residential moving experiences only after age 12 was associated with poor academic performance among university students.

\section{The Moderating Role of Resilience and Family Income}

The results in Model 3 showed that the main effect of family income was significant with higher family income predicting lower academic performance, $b=-0.123, S E=0.058, t=-2.128$, $p=0.033,95 \% \mathrm{CI}$ : $[-0.236,-0.010]$. In contrast, the main effect of resilience was not significant, $b=-0.197, S E=0.153, t=-1.285$, $p=0.199$, 95\%CI: $[-0.498,0.104]$. The interaction between resilience and family income was not significant, $b=0.006$, $S E=0.086, t=0.073, p=0.942,95 \% \mathrm{CI}$ : [ $-0.162,0.175]$.

Regarding the effects associated with residential mobility in early childhood, its main effect was not significant, $b=-0.116$, $S E=0.149, t=-0.776, p=0.438,95 \% \mathrm{CI}=[-0.409,0.177]$. All interactions were not significant: the interaction effect between residential mobility in early childhood and resilience: $b=0.077$, $S E=0.243, t=0.315, p=0.753,95 \% \mathrm{CI}$ : [ $-0.400,0.553]$; the interaction effect between residential mobility in early childhood and family income: $b=0.110, S E=0.085, t=1.291, p=0.197$, 95\%CI: $[-0.057,0.276]$; the 3-way interaction effect of resilience, family income, and residential mobility in early childhood: $b=-0.062, S E=0.142, t=-0.436, p=0.663,95 \% \mathrm{CI}$ : [-0.340, 0.217].

Regarding the effects associated with residential mobility in late childhood, its main effect was not significant, $b=0.008$, $S E=0.145, t=0.056, p=0.955,95 \% \mathrm{CI}=[-0.276,0.293]$. All interactions were not significant: the interaction between residential mobility in late childhood and resilience, $b=-0.157$, $S E=0.223, t=-0.702, p=0.483,95 \% \mathrm{CI}$ : [-0.594, 0.281], the interaction between residential mobility in late childhood and family income, $b=-0.083, S E=0.088, t=-0.950$, $p=0.342,95 \% \mathrm{CI}:[-0.256,0.089]$, the 3 -way interaction of resilience, family income, and residential mobility in late childhood, $b=-0.199, S E=.133, t=-1.494, p=0.135,95 \% \mathrm{CI}$ : [-0.460, 0.062].

Regarding the effects associated with residential mobility in adolescence, its main effect was significant, in which it significantly predicted poorer academic performance, $b=-0.315$, $S E=0.137, t=-2.305, p=0.021,95 \% \mathrm{CI}$ : [ $-0.583,-0.047]$. All interactions were not significant: the interaction between residential mobility in adolescence and resilience: $b=-0.138$, $S E=0.187, t=-0.738, p=0.460,95 \% \mathrm{CI}$ : [ $-0.506,0.229]$; the interaction between residential mobility in adolescence and family income: $b=-0.084, S E=0.080, t=-1.052$, 
TABLE 2 | The results of the linear regression models tested for mental health and academic performance.

\begin{tabular}{|c|c|c|c|c|}
\hline & \multicolumn{2}{|c|}{ Mental health } & \multicolumn{2}{|c|}{$\begin{array}{c}\text { Academic } \\
\text { performance }\end{array}$} \\
\hline & $b$ & $S E$ & $b$ & $S E$ \\
\hline \multicolumn{5}{|l|}{ Model 1} \\
\hline Constant & $159.12^{* * *}$ & 0.704 & $79.421^{* * *}$ & 0.1 \\
\hline MEC & 0.464 & 1.029 & -0.154 & 0.146 \\
\hline MLC & 2.193* & 1.017 & 0.001 & 0.144 \\
\hline MA & $1.954^{*}$ & 0.942 & $-0.336^{*}$ & 0.136 \\
\hline$F$ & $5.371^{* *}$ & & $3.127^{*}$ & \\
\hline Adjusted $R^{2}$ & 0.004 & & 0.002 & \\
\hline \multicolumn{5}{|l|}{ Model 2} \\
\hline Constant & $156.849^{* * *}$ & 1.136 & $77.461^{* * *}$ & 0.152 \\
\hline MEC & 0.559 & 1.031 & -0.206 & 0.141 \\
\hline MLC & $1.885+$ & 1.02 & 0.047 & 0.139 \\
\hline MA & $2.273^{*}$ & 0.942 & $-0.278^{*}$ & 0.13 \\
\hline Gender & $3.258 *$ & 1.451 & $3.244^{* * *}$ & 0.198 \\
\hline Age & -0.212 & 0.231 & $-0.468^{* * *}$ & 0.098 \\
\hline$F$ & $4.401^{* *}$ & & $63.622^{* * *}$ & \\
\hline Adjusted $R^{2}$ & 0.005 & & 0.094 & \\
\hline \multicolumn{5}{|l|}{ Model 3} \\
\hline Constant & $159.04^{* * *}$ & 0.643 & $79.434^{* * *}$ & 0.101 \\
\hline MEC & 0.588 & 0.945 & -0.116 & 0.149 \\
\hline MLC & $1.542^{\dagger}$ & 0.932 & 0.008 & 0.145 \\
\hline MA & $1.532^{\dagger}$ & 0.86 & $-0.315^{*}$ & 0.137 \\
\hline Resilience & $-26.292^{* * *}$ & 0.989 & -0.197 & 0.153 \\
\hline Family income & $-1.823^{* * *}$ & 0.364 & $-0.123^{*}$ & 0.058 \\
\hline Resilience*MEC & 1.486 & 1.558 & 0.077 & 0.243 \\
\hline Resilience*MLC & -1.901 & 1.429 & -0.157 & 0.223 \\
\hline Resilience*MA & $-2.42^{*}$ & 1.211 & -0.138 & 0.187 \\
\hline Family income*MEC & 0.012 & 0.528 & 0.11 & 0.085 \\
\hline Family income*MLC & -0.223 & 0.547 & -0.083 & 0.088 \\
\hline Family income*MA & $-1.13^{*}$ & 0.482 & -0.084 & 0.08 \\
\hline Resilience*Family income & $1.301^{*}$ & 0.546 & 0.006 & 0.086 \\
\hline Resilience*Family income*MEC & 0.403 & 0.901 & -0.062 & 0.142 \\
\hline Resilience*Family income*MLC & 1.101 & 0.844 & -0.199 & 0.133 \\
\hline Resilience*Family income*MA & $1.701^{*}$ & 0.723 & -0.081 & 0.115 \\
\hline$F$ & $55.025^{* * *}$ & & $1.845^{*}$ & \\
\hline Adjusted $R^{2}$ & 0.179 & & 0.004 & \\
\hline \multicolumn{5}{|l|}{ Model 4} \\
\hline Constant & $159.023^{* * *}$ & 1.037 & $77.496 * * *$ & 0.153 \\
\hline MEC & 0.742 & 0.947 & -0.166 & 0.144 \\
\hline MLC & 1.269 & 0.934 & 0.053 & 0.14 \\
\hline MA & $1.755^{*}$ & 0.86 & $-0.254^{\dagger}$ & 0.131 \\
\hline Resilience & $-26.479^{* * *}$ & 0.999 & 0.035 & 0.149 \\
\hline Family income & $-1.803^{* * *}$ & 0.365 & $-0.118^{*}$ & 0.056 \\
\hline Resilience*MEC & 0.955 & 1.567 & 0.011 & 0.235 \\
\hline Resilience*MLC & -1.804 & 1.442 & -0.146 & 0.217 \\
\hline Resilience*MA & $-2.268+$ & 1.216 & -0.055 & 0.181 \\
\hline Family income*MEC & 0.031 & 0.528 & 0.094 & 0.082 \\
\hline Family income*MLC & -0.315 & 0.548 & -0.081 & 0.085 \\
\hline Family income*MA & $-1.1^{*}$ & 0.481 & -0.08 & 0.077 \\
\hline Resilience*Family income & $1.15^{*}$ & 0.55 & 0.012 & 0.083 \\
\hline
\end{tabular}

TABLE 2 | Continued

\begin{tabular}{|c|c|c|c|c|}
\hline & \multicolumn{2}{|c|}{ Mental health } & \multicolumn{2}{|c|}{$\begin{array}{c}\text { Academic } \\
\text { performance }\end{array}$} \\
\hline & $b$ & $S E$ & $b$ & $S E$ \\
\hline Resilience*Family income*MEC & 0.465 & 0.902 & -0.097 & 0.137 \\
\hline Resilience*Family income*MLC & 0.908 & 0.853 & -0.181 & 0.129 \\
\hline Resilience*Family income*MA & $1.851^{*}$ & 0.727 & -0.045 & 0.111 \\
\hline Gender & -0.314 & 1.326 & $3.206^{* * *}$ & 0.2 \\
\hline Age & -0.197 & 0.21 & $-0.494^{* * *}$ & 0.098 \\
\hline$F$ & $48.422^{* * *}$ & & $19.549^{* * *}$ & \\
\hline Adjusted $R^{2}$ & 0.18 & & 0.095 & \\
\hline
\end{tabular}

MEC, MLC, and MA represent residential mobility in early childhood, residential mobility in late childhood, and residential mobility in adolescence, respectively. Unstandardized coefficients and standard errors are reported. ${ }^{\dagger} p<0.1 ;{ }^{*} p<0.05$; ${ }^{* *} p<0.01 ;{ }^{* * *} p<0.001$.

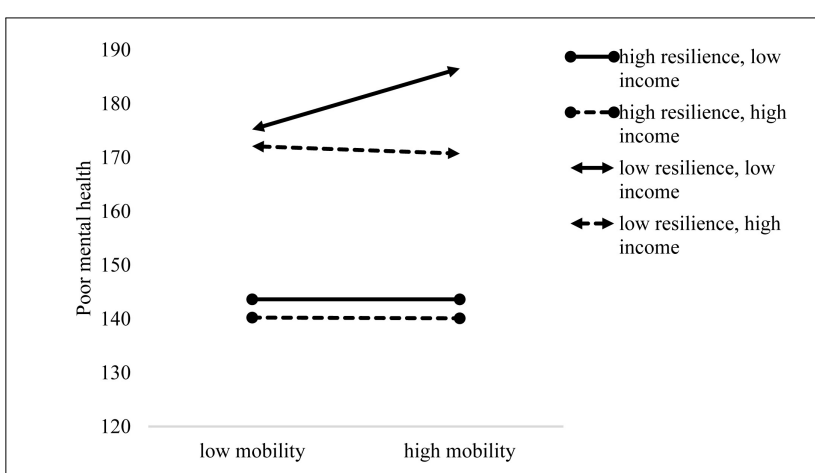

FIGURE 1 | The interaction effect of resilience, family income, and residential mobility in adolescence in predicting university students' mental health.

$p=0.293$, 95\%CI: $[-0.241,0.073]$; the 3-way interaction of resilience, family income and residential mobility in adolescence: $b=-0.081, S E=0.115, t=-0.707, p=0.479,95 \% \mathrm{CI}$ : [-0.307, 0.144].

The results remained similar when the effect of age and gender were controlled (see Table 1, Model 4).

\section{DISCUSSION}

Previous research mostly investigated the relations between residential mobility and its outcomes such as mental health and academic performance without pinpointing the unique effects of residential mobility at different developmental stages. In the current research. First, we demonstrated that there was a sensitive period of moving on mental health. More moving experiences after age 6 was associated with poorer mental health of university students, whereas moving experiences before age 6 did not have notable impacts on mental health. Furthermore, resilience and family income moderated the negative effects of residential mobility in adolescence on mental health, in which high resilience or/and family income buffered the negative impact of residential mobility. Regarding academic performance, more moving experiences after age 12 predicted poorer academic 
performance of university students, and this pattern was not moderated by resilience or family income. Taken together, the findings suggested that residential mobility at different developmental stages had unique impacts on university students' mental health and academic performance.

\section{Implications}

\section{Theoretical Implications}

The current research had important implications for residential mobility research. On the one hand, some recent studies indicated that residential mobility can lead to positive consequences, including eliminating in-group favoritism in prosocial behaviors (Li et al., 2019), and promoting donations to a natural disaster ( $\mathrm{Li}$ et al., unpublished). On the other hand, previous research generally suggests that residential mobility has negative consequences on individuals' well-being or the overall well-being of society (Oishi, 2010; Oishi and Graham, 2010; Mok et al., 2016; Morris et al., 2018). In line with previous work, the current research found that residential mobility was associated with poor mental health and poor academic performance in the long run. Taking all existing evidence together, it suggests that whether the effect of residential mobility is positive or negative may be domain-specific. Future research should carefully explore what domains would be benefited or impaired by residential mobility.

Related to the above discussion, the current research provided a perspective to understand what domains would be impaired by residential mobility. We found a sensitive period of moving when we considered the relation of residential mobility at different developmental stages to mental health and academic performance among university students. Previous research primarily studied the overall effect of residential mobility on different domains (Leventhal and Newman, 2010; Boynton-Jarrett et al., 2013; Tunstall et al., 2014a,b; Glasheen et al., 2017). The current research highlighted the importance of the age at which people move, as moving experiences may bring greater challenges to the achievement of specific developmental goals suggested by some classic developmental theories (e.g., Erikson, 1963; Lin, 1983). Our findings showed that moving experiences after age 6 was associated with poorer mental health and moving experiences after 12 was associated with poorer academic performance among university students, which suggested that the sensitive period of moving could be different across domains. Similar to other research lines related to sensitive period (e.g., second language learning, and acculturation; Cheung et al., 2011; Blakemore and Mills, 2014), changes at certain time period in one's life could bring stronger influence on some specific psychological processes. Future research should continue to explore how moving experiences at different developmental stages would shape people's psychological processes in different domains.

\section{Practical Implications}

In addition to theoretical implications, the current research offered some important practical implications. Observing the negative effects of residential mobility on mental health and academic performance, parents should try to move as less as possible. However, residential mobility for better education or job opportunities has become an inevitable trend in modern society. The current research suggested that, instead of aborting the moving plan, parents can choose the right time to move, which could minimize the negative impact of residential mobility on mental health and academic performance in later lives.

In addition, the current research demonstrated the importance of two coping resources, in which having high residence or/and high income weakened the negative effect of residential mobility on mental health. These findings indicated that different types of capital, resilience as an important source of psychological capital and family income as an important source of physical capital, could buffer the negative effect of socio-ecological factors. First, consistent with previous studies (Albrecht and Teachman, 2003; Webb et al., 2016), family income is an important indicator of how much support or resources students can obtain to cope with difficulties associated with residential mobility (Rabe and Taylor, 2010), which can in turn promote better mental health. Despite its importance, it would be difficult to change students' family income. More importantly, effective programs that can be implemented at school for promoting resilience, which was found to buffer the negative effect of residential mobility independently in the current research, are available. For instance, universities can implement group counseling service (Walsh, 2002), which may enhance students' resilience and in turn help those with moving histories to attain better adjustments.

\section{Limitations and Future Directions}

The current research had some limitations. First, the data in the current research were correlational, which did not provide causal evidence supporting the influence of residential mobility on mental health, and academic performance. Future studies should adopt a longitudinal design to observe how participants' residential mobility at different developmental stages may potentially interact with their resilience and family income in affecting their experiences across different domains. Second, residential mobility may have different causes, which could be positive (e.g., seeking better employment, seeking better education environment), or negative (e.g., divorce). The moving experiences that differ in moving motives may have different effects on people's psychological processes and behaviors (Rabe and Taylor, 2010). To fully understand the influence of residential mobility, we should carefully distinguish different types of moving and examine how different types of moving would affect people across domains in future research. Third, despite of a large sample size, we only conducted one study to test our research questions. Thus more studies are needed to check whether the findings could be replicated in other samples with different demographic or cultural characteristics. Fourth, we acknowledged that online studies could not strictly control the environmental characteristics as well as laboratory studies do. However, since the items in the measures for mental health are personally sensitive, using online surveys can ensure privacy, which can encourage participants to provide authentic response. Finally, we did not find a significant moderator that can alleviate the negative effects of moving on academic performance. Future 
research may consider investigating the role of other individual characteristics, such as self-esteem, in reducing the negative impact of residential mobility.

\section{ETHICS STATEMENT}

This study was carried out with written informed consent from all participants. All participants gave written informed consent in accordance with the Declaration of Helsinki. The protocol was approved by the Departmental Ethics Review Board of Department of Psychology, Sun Yat-sen University.

\section{REFERENCES}

Adam, E. K. (2004). Beyond quality: parental and residential stability and children's adjustment. Curr. Direct. Psychol. Sci. 13, 210-213. doi: 10.1111/j.0963-7214. 2004.00310.x

Aiken, L. S., and West, S. G. (1991). Multiple Regression Testing and Interpreting Interactions. Newbury Park, CA: Sage.

Albrecht, C., and Teachman, J. D. (2003). Childhood living arrangements and the risk of premarital intercourse. J. Fam. Issues 24, 867-894. doi: 10.1177/ $0192513 X 03252731$

Anthony, E. J. (1974). “The syndrome of the psychologically invulnerable child," in The Child in his Family: Children at Psychiatric Risk, eds E. J. Anthony and C. Koupernik (Oxford: John Wiley).

Armsden, G. C., and Greenberg, M. T. (1987). The inventory of parent and peer attachment: individual differences and their relationship to psychological well-being in adolescence. J. Youth Adoles. 16, 427-454. doi: 10.1177/ 2158244015571639

Bakeman, R., and Brown, J. V. (1980). Early interaction: consequences for social and mental development at three years. Child Dev. 51, 437-447. doi: 10.2307/ 1129277

Baldassare, M., Knight, R., and Swan, S. (1979). Urban service and environmental stressor: the impact of the bay area rapid transit system (BART) on residential mobility. Environ. Behav. 11, 435-450. doi: 10.1177/0013916579114001

Basolo, V., and Yerena, A. (2017). Residential mobility of low-income, subsidized households: a synthesis of explanatory frameworks. Hous. Stud. 32, 841-862. doi: 10.1080/02673037.2016.1240762

Bembenutty, H. (1999). Sustaining motivation and academic goals: the role of academic delay of gratification. Learn. Individ. Differ. 11, 233-257. doi: 10.1016/ S1041-6080(99)80002-8

Berzonsky, M. D., and Kuk, L. S. (2005). Identity style, psychosocial maturity, and academic performance. Personal. Individ. Differ. 39, 235-247. doi: 10.1016/j. socscimed.2012.09.007

Blakemore, S. J., and Mills, K. L. (2014). Is adolescence a sensitive period for sociocultural processing? Annu. Rev. Psychol. 65, 187-207. doi: 10.1146/ annurev-psych-010213-115202

Bonanno, G. A. (2004). Loss, trauma, and human resilience: have we underestimated the human capacity to thrive after extremely aversive events? Am. Psychol. 59, 20-28. doi: 10.1037/0003-066X.59.1.20

Boynton-Jarrett, R., Hair, E., and Zuckerman, B. (2013). Turbulent times: effects of turbulence and violence exposure in adolescence on high school completion, health risk behavior, and mental health in young adulthood. Soc. Sci. Med. 95, 77-86. doi: 10.1016/j.socscimed.2012.09.007

Brown, D., Benzeval, M., Gayle, V., Macintyre, S., O'reilly, D., and Leyland, A. H. (2012). Childhood residential mobility and health in late adolescence and adulthood: findings from the West of Scotland Twenty-07 Study. J. Epidemiol. Community Health 66, 942-950. doi: 10.1136/jech-2011-200316

Bucci, S., Roberts, N. H., Danquah, A. N., and Berry, K. (2015). Using attachment theory to inform the design and delivery of mental health services: a systematic review of the literature. Psychol. Psychother. 88, 1-20. doi: 10.1111/papt.12029

Bures, R. M. (2003). Childhood residential stability and health at midlife. Am. J. Public Health 93, 1144-1148. doi: 10.2105/AJPH.93.7.1144

\section{AUTHOR CONTRIBUTIONS}

ML and LL designed the study. ML collected data. ML and W-QL analyzed the data. ML, W-QL, and LL wrote the manuscript. LL supervised the project.

\section{FUNDING}

This study was supported by the Youth Program of National Social Science Foundation of China (\#16CMZ035) awarded to ML.

Campbell, J. D., and Lavallee, L. F. (1993). "Who am I? The role of self-concept confusion in understanding the behavior of people with low self-esteem," in Self-Esteem: The Puzzle of Low Self-Regard, ed. R. F. Baumeister (New York, NY: Plenum), 3-20.

Campbell-Sills, L., Cohan, S. L., and Stein, M. B. (2006). Relationship of resilience to personality, coping, and psychiatric symptoms in young adults. Behav. Res. Ther. 44, 585-599. doi: 10.1016/j.brat.2005.05.001

Carver, C. S. (1998). Resilience and thriving: issues, models, and linkages. J. Soc. Issues 54, 245-266. doi: 10.1111/j.1540-4560.1998.tb01217.x

Cassady, J. C., and Johnson, R. E. (2002). Cognitive test anxiety and academic performance. Contemp. Educ. Psychol. 27, 270-295. doi: 10.1006/ceps.2001. 1094

Cheung, B. Y., Chudek, M., and Heine, S. J. (2011). Evidence for a sensitive period for acculturation: younger immigrants report acculturating at a faster rate. Psychol. Sci. 22, 147-152. doi: 10.1177/0956797610394661

Coley, R. L., Sims, J., Dearing, E., and Spielvogel, B. (2018). Locating economic risks for adolescent mental and behavioral health: poverty and affluence in families, neighborhoods, and schools. Child Dev. 89, 360-369. doi: 10.1111/cdev.12771

Cordes, S. A., Schwartz, A. E., Stiefel, L., and Zabel, J. (2016). Is neighborhood destiny? Exploring the link between neighbor-hood mobility and student outcomes. Urban Stud. 53, 400-417. doi: 10.1177/0042098014563469

Crittenden, P. M. (1992). Children's strategies for coping with adverse home environments: an interpretation using attachment theory. Child Abuse Negl. 16, 329-343. doi: 10.1016/0145-2134(92)90043-Q

Culler, R. E., and Holahan, C. J. (1980). Test anxiety and academic performance: the effects of study-related behaviors. J. Educ. Psychol. 72, 16-20. doi: 10.1037/ 0022-0663.72.1.16

Derogatis, L. R., Lipman, R. S., and Covi, L. (1973). The SCL-90: an outpatient psychiatric rating scale: preliminary report. Psychopharmacol. Bull. 9, 13-28.

DeWit, D. J. (1998). Frequent childhood geographic relocation: its impact on drug use initiation and the development of alcohol and other drug-related problems among adolescents and young adults. Addict. Behav. 23, 623-634. doi: 10.1016/S0306-4603(98)00023-9

Duckworth, A. L., and Seligman, M. E. (2005). Self-discipline outdoes IQ in predicting academic performance of adolescents. Psychol. Sci. 16, 939-944. doi: 10.1111/j.1467-9280.2005.01641.x

Dumont, M., and Provost, M. A. (1999). Resilience in adolescents: protective role of social support, coping strategies, self-esteem, and social activities on experience of stress and depression. J. Youth Adoles. 28, 343-363. doi: 10.1080/ 00981380802599216

Eggleston, C. M., and Oishi, S. (2013). "Is happiness a moving target? The relationship between residential mobility and meaning in life," in The Experience of Meaning in Life: Perspectives from the Psychological Sciences, eds J. Hicks and C. Routledge (New York, NY: Springer Press), 333-345.

Erikson, E. H. (1963). Youth: Change and Challenge. New York, NY: Norton.

Erikson, E. H. (1968). Identity: Youth and Crisis. New York, NY: Norton.

Freud, S. (1940). An Outline of Psychoanalysis, Standard Edition, Vol. 23. London: Hogarth Press, 144-207.

Friborg, O., Barlaug, D., Martinussen, M., Rosenvinge, J. H., and Hjemdal, O. (2005). Resilience in relation to personality and intelligence. Int. J. Methods Psychiatr. Res. 14, 29-42. doi: 10.1002/mpr.15 
Giallo, R., and Gavidia-Payne, S. (2006). Child, parent and family factors as predictors of adjustment for siblings of children with a disability. J. Intellect. Disabil. Res. 50, 937-948. doi: 10.1111/j.1365-2788.2006.00928.x

Gilman, S. E., Kawachi, I., Fitzmaurice, G. M., and Buka, S. L. (2003). Socioeconomic status, family disruption and residential stability in childhood: relation to onset, recurrence and remission of major depression. Psychol. Med. 33, 1341-1355. doi: 10.1017/S0033291703008377

Glasheen, C., Forman-Hoffman, V. L., and Williams, J. (2017). Residential mobility, transience, depression, and marijuana use initiation among adolescents and young adults. Subst. Abuse 11, 1-10. doi: 10.1177/1178221817711415

Glew, G. M., Fan, M. Y., Katon, W., Rivara, F. P., and Kernic, M. A. (2005). Bullying, psychosocial adjustment, and academic performance in elementary school. Arch. Pediatr. Adoles. Med. 159, 1026-1031. doi: 10.1001/archpedi.159. 11.1026

Green, J. G., McLaughlin, K. A., Berglund, P. A., Gruber, M. J., Sampson, N. A., Zaslavsky, A. M., et al. (2010). Childhood adversities and adult psychiatric disorders in the national comorbidity survey replication I: associations with first onset of DSM-IV disorders. Arch. Gen. Psychiatry 67, 113-123. doi: 10.1001/ archgenpsychiatry.2009.187

Greenblatt, M., Becerra, R. M., and Serafetinides, E. A. (1982). Social networks and mental health: an overview. Am. J. Psychiatry 139, 977-984. doi: 10.1176/ajp. 139.8.977

Hagger, M. S., Wood, C., Stiff, C., and Chatzisarantis, N. L. (2010). Ego depletion and the strength model of self-control: a meta-analysis. Psychol. Bull. 136, 495-525. doi: 10.1037/a0019486

Hardy, C. L., Bukowski, W. M., and Sippola, L. K. (2002). Stability and change in peer relationships during the transition to middle-level school. J. Early Adoles. 22, 117-142. doi: 10.1177/0272431602022002001

Hendershott, A. B. (1989). Residential mobility, social support and adolescent self-concept. Adolescence 24, 217-232.

Herbers, J. E., Cutuli, J. J., Supkoff, L. M., Heistad, D., Chan, C. K., Hinz, E., et al. (2012). Early reading skills and academic achievement trajectories of students facing poverty, homelessness, and high residential mobility. Educ. Res. 41, 366-374. doi: 10.3102/0013189X12445320

Hilton, S. L., and van Minnen, C. A. (2002). "The rocky road to greener grass: mobility in U.S. history: an introduction," in Nation on the Move: Mobility in U.S. History, eds C. A. van Minnen and S. L. Hilton (Amsterdam: VU University Press), 1-15.

I.B.M Corp (2017). IBM SPSS Statistics: Version 25. Chicago, IL: IBM Corporation. Jelenic, M. (2014). Identity status: The impact on academic performance. Dissertation. Ipswich, MA: EBSCOhost.

Jelleyman, T., and Spencer, N. (2008). Residential mobility in childhood and health outcomes: a systematic review. J. Epidemiol. Commun. Health 62, 584-592. doi: 10.1136/jech.2007.060103

Kawachi, I., and Berkman, L. F. (2001). Social ties and mental health. J. Urban Health 78, 458-467. doi: 10.1093/jurban/78.3.458

Keogh, E., Bond, F. W., and Flaxman, P. E. (2006). Improving academic performance and mental health through a stress management intervention: outcomes and mediators of change. Behav. Res. Ther. 44, 339-357. doi: 10.1016/ j.brat.2005.03.002

Kessler, R. C., and Magee, W. J. (1993). Childhood adversities and adult depression: basic patterns of association in a US national survey. Psychol. Med. 23, 679-690. doi: 10.1017/S0033291700025460

Kessler, R. C., McLaughlin, K. A., Green, J. G., Gruber, M. J., Sampson, N. A., Zaslavsky, A. M., et al. (2010). Childhood adversities and adult psychopathology in the WHO World Mental Health Surveys. Br. J. Psychiatry 197, 378-385. doi: 10.1192/bjp.bp.110.080499

Kroger, J. (1989). Identity in Adolescence: The Balance between Self and Other. London: Routledge.

Ladd, G. W., and Troop-Gordon, W. (2003). The role of chronic peer difficulties in the development of children's psychological adjustment problems. Child Dev. 74, 1344-1367. doi: 10.1111/1467-8624.00611

Langenkamp, A. G. (2016). Effects of school mobility on adolescent social ties and academic adjustment. Youth Soc. 48, 810-833. doi: 10.1177/0044118X13517908

Letourneau, N. L., Duffett-Leger, L., Levac, L., Watson, B., and Young-Morris, C. (2013). Socioeconomic status and child development: a meta-analysis. J. Emot. Behav. Disord. 21, 211-224. doi: 10.1177/1063426611421007
Leventhal, T., and Newman, S. (2010). Housing and child development. Child. Youth Serv. Rev. 32, 1165-1174. doi: 10.1016/j.childyouth.2010.03.008

Li, L. M. W. (2017). Social class, social capital and residential mobility in China. Soc. Indic. Res. 132, 1117-1129. doi: 10.1007/s11205-016-1339-9

Li, W. Q., Li, L. M. W., and Li, M. (2019). Residential mobility reduces ingroup favouritism in prosocial behaviour. Asian J. Soc. Psychol. 22, 3-17. doi: 10.1111/ ajsp. 12338

Li, Y., Ren, Z., and Jiang, G. (2016). Meta-analysis on the mental health of the Chinese policemen of public security organization. Adv. Psychol. Sci. 24, 692-706. doi: 10.3724/SP.J.1042.2016.00692

Lin, C. D. (1983). The drive of psychological development of children and adolescents. J. Beijing Norm. Univ. 1, 24-29.

Lun, J., Oishi, S., and Tenney, E. R. (2012). Residential mobility moderates preferences for egalitarian versus loyal helpers. J. Exp. Soc. Psychol. 48, 291-297. doi: 10.1016/j.jesp.2011.09.002

Magdol, L., and Bessel, D. R. (2003). Social capital, social currency, and portable assets: the impact of residential mobility on exchanges of social support. Pers. Relatsh. 10, 149-170. doi: 10.1111/1475-6811.00043

Masten, A. S. (2007). Resilience in developing systems: progress and promise as the fourth wave rises. Dev. Psychopathol. 19, 921-930. doi: 10.1017/ S0954579407000442

McGloin, J. M., and Thomas, K. J. (2016). Incentives for collective deviance: group size and changes in perceived risk, cost, and reward. Criminology 54, 459-486. doi: 10.1111/1745-9125.12111

Mickelson, K. D., Kessler, R. C., and Shaver, P. R. (1997). Adult attachment in a nationally representative sample. J. Personal. Soc. Psychol. 73, 1092-1106. doi: 10.1037/0022-3514.73.5.1092

Mok, P. L., Webb, R. T., Appleby, L., and Pedersen, C. B. (2016). Full spectrum of mental disorders linked with childhood residential mobility. J. Psychiatr. Res. 78, 57-64. doi: 10.1016/j.jpsychires.2016.03.011

Mollborn, S., Lawrence, E., and Root, E. D. (2018). Residential mobility across early childhood and children's kindergarten readiness. Demography 55, 485-510.

Morris, T., Manley, D., and Sabel, C. E. (2018). Residential mobility: towards progress in mobility health research. Prog. Hum. Geogr. 42, 112-133. doi: 10. $1177 / 0309132516649454$

Oishi, S. (2010). The psychology of residential mobility implications for the self, social relationships, and well-being. Perspect. Psychol. Sci. 5, 5-21. doi: 10.1177/ 1745691609356781

Oishi, S., and Graham, J. (2010). Social ecology lost and found in psychological science. Perspect. Psychol. Sci. 5, 356-377. doi: 10.1177/1745691610374588

Oishi, S., Kesebir, S., Miao, F. F., Talhelm, T., Endo, Y., Uchida, Y., et al. (2013). Residential mobility increases motivation to expand social network: but why? J. Exp. Soc. Psychol. 49, 217-223. doi: 10.1016/j.jesp.2012.10.008

Oishi, S., Lun, J., and Sherman, G. D. (2007a). Residential mobility, self-concept, and positive affect in social interactions. J. Personal. Soc. Psychol. 93, 131-141. doi: 10.1037/0022-3514.93.1.131

Oishi, S., Rothman, A. J., Snyder, M., Su, J., Zehm, K., Hertel, A. W., et al. (2007b). The socioecological model of procommunity action: the benefits of residential stability. J. Personal. Soc. Psychol. 93, 831-844. doi: 10.1037/0022-3514.93.5.831

Oishi, S., and Schimmack, U. (2010). Residential mobility, well-being, and mortality. J. Personal. Soc. Psychol. 98, 980-994. doi: 10.1037/a0019389

Oishi, S., and Talhelm, T. (2012). Residential mobility: what psychological research reveals. Curr. Direct. Psychol. Sci. 21, 425-430. doi: 10.1177/0963721412460675

Oishi, S., Whitchurch, E., Miao, F. F., Kurtz, J., and Park, J. (2009). 'Would I be happier if I moved?' Retirement status and cultural variations in the anticipated and actual levels of happiness. J. Posit. Psychol. 4, 437-446. doi: $10.1080 / 17439760903271033$

Power, C., and Hertzman, C. (1997). Social and biological pathways linking early life and adult disease. Br. Med. Bull. 53, 210-221. doi: 10.1093/oxfordjournals. bmb.a011601

R Core Team (2018). R: A language and environment for statistical computing. Vienna: R Foundation for Statistical Computing

Rabe, B., and Taylor, M. (2010). Residential mobility, quality of neighbourhood and life course events. J. R. Stat. Soc. Ser. A Stat. Soc. 173, 531-555. doi: 10.1111/j. 1467-985X.2009.00626.x

Ramos-Sánchez, L., and Nichols, L. (2007). Self-efficacy of first-generation and non-first-generation college students: the relationship with academic 
performance and college adjustment. J. Coll. Counsel. 10, 6-18. doi: 10.1002/ j.21611882.2007.tb00002.x

Reiss, F. (2013). Socioeconomic inequalities and mental health problems in children and adolescents: a systematic review. Soc. Sci. Med. 90, 24-31. doi: 10.1016/j.socscimed.2013.04.026

Repper, J., and Carter, T. (2011). A review of the literature on peer support in mental health services. J. Ment. Health 20, 392-411. doi: 10.3109/09638237. 2011.583947

Ruback, R. B., Pandey, J., Begum, H. A., Tariq, N., and Kamal, A. (2004). Motivations for and satisfaction with migration: an analysis of migrants to New Delhi, Dhaka, and Islamabad. Environ. Behav. 36, 814-838. doi: 10.1177/ 0013916504264948

Ruddy, R., Audin, K., and Barkham, M. (2005). How to develop interorganisational research networks in mental health: a systematic review. J. Ment. Health 14, 7-23. doi: 10.1080/09638230500048073

Rutter, M. (1985). Resilience in the face of adversity: protective factors and resistance to psychiatric disorder. Br. J. Psychiatry 147, 598-611. doi: 10.1192/ bjp.147.6.598

Sampson, R. J. (1988). Local friendship ties and community attachment in mass society: a multilevel systemic model. Am. Sociol. Rev. 53, 766-779. doi: 10.2307/ 2095822

Scanlon, E., and Devine, K. (2001). Residential mobility and youth wellbeing: research, policy, and practice issues. J. Sociol. Soc. Welf. 28, 119-138.

Schmitt, S. A., Finders, J. K., and McClelland, M. M. (2015). Residential mobility, inhibitory control, and academic achievement in preschool. Early Educ. Dev. 26, 189-208. doi: 10.1080/10409289.2015.975033

Seipp, B. (1991). Anxiety and academic performance: a meta-analysis of findings. Anxiety Res. 4, 27-41. doi: 10.1080/08917779108248762

Sharkey, P., and Sampson, R. J. (2010). Destination effects: residential mobility and trajectories of adolescent violence in a stratified metropolis. Criminology 48, 639-681. doi: 10.1111/j.1745-9125.2010.00198.x

Sherman, D. K., Hartson, K. A., Binning, K. R., Purdie-Vaughns, V., Garcia, J., Taborsky-Barba, S., et al. (2013). Deflecting the trajectory and changing the narrative: how self-affirmation affects academic performance and motivation under identity threat. J. Personal. Soc. Psychol. 104, 591-618. doi: 10.1037/ a0031495

Shiraga, K., Kawano, K., Masaki, N., Matoba, Y., and Takeshima, T. (2013). Mental health and involvement of residents of the life support advisor in iwate prefecture after the Great East Japan Earthquake: suicide prevention in the affected area. J. Ment. Health 59, 75-83.

Shklovski, I. (2007). Residential Mobility, Technology \& Social Ties. Dissertation. Pittsburgh, PA: Carnegie Melon University.

Smith, B. W., Dalen, J., Wiggins, K., Tooley, E., Christopher, P., and Bernard, J. (2008). The brief resilience scale: assessing the ability to bounce back. Int. J. Behav. Med. 15, 194-200. doi: 10.1080/10705500802222972

Troy, A. S., and Mauss, J. B. (2011). "Resilience in the face of stress: emotion regulation as a protective factor," in Resilience and Mental Health: Challenges Across the Lifespan, eds S. M. Southwick, B. T. Litz, D. Charney, and M. J. Friedman (New York, NY: Cambridge University Press), 30-44.
Tseliou, F., Maguire, A., Donnelly, M., and O'reilly, D. (2016). The impact of childhood residential mobility on mental health outcomes in adolescence and early adulthood: a record linkage study. J. Epidemiol. Community Health 70, 278-285. doi: 10.1136/jech-2015-206123

Tugade, M. M., and Fredrickson, B. L. (2004). Resilient individuals use positive emotions to bounce back from negative emotional experiences. J. Personal. Soc. Psychol. 86, 320-333. doi: 10.1037/0022-3514.86.2.320

Tunstall, H., Mitchell, R., Pearce, J., and Shortt, N. (2014a). The general and mental health of movers to more- and less- disadvantaged socio-economic and physical environments within the UK. Soc. Sci. Med. 118, 97-107. doi: 10.1016/j.socscimed.2014.07.038

Tunstall, H., Pearce, J. R., Shortt, N. K., and Mitchell, R. J. (2014b). Residential mobility and the association between physical environment disadvantage and general and mental health. J. Public Health 37, 563-572. doi: 10.1093/pubmed/ fdu058

Tusaie, K., and Dyer, J. (2004). Resilience: a historical review of the construct. Holist. Nurs. Pract. 18, 3-10. doi: 10.1097/00004650-200401000-00002

Voight, A., Giraldo-García, R., and Shinn, M. (2017). The effects of residential mobility on the education outcomes of urban middle school students and the moderating potential of civic engagement. Urban Educ. 8, 1-22. doi: 10.1177/ 0042085917721956

Voight, A., Shinn, M., and Nation, M. (2012). The longitudinal effects of residential mobility on the academic achievement of urban elementary and middle school students. Educ. Res. 41, 385-392. doi: 10.3102/0013189X12442239

Wadsworth, M. E. J. (1997). Health inequalities in the life course perspective. Soc. Sci. Med. 44, 859-869. doi: 10.1016/S0277-9536(96)00187-6

Walsh, F. (2002). A family resilience framework: innovative practice applications. Fam. Relat. 51, 130-137. doi: 10.1111/j.1741-3729.2002.00130.x

Webb, R. T., Pedersen, C. B., and Mok, P. L. (2016). Adverse outcomes to early middle age linked with childhood residential mobility. Am. J. Prevent. Med. 51, 291-300. doi: 10.1016/j.amepre.2016.04.011

Widom, C. S., Czaja, S. J., Kozakowski, S. S., and Chauhan, P. (2018). Does adult attachment style mediate the relationship between childhood maltreatment and mental and physical health outcomes? Child Abuse Negl. 76, 533-545. doi: 10.1016/j.chiabu.2017.05.002

Ye, Z., Chai, X., Guo, H., Weng, H., and Lin, D. (2017). The relationship between mobility, educational settings, resilience and loneliness among migrant children: a longitudinal study. Psychol. Dev. Educ. 33, 595-604. doi: 10.16187/j. cnki.issn1001-4918.2017.05.10

Conflict of Interest Statement: The authors declare that the research was conducted in the absence of any commercial or financial relationships that could be construed as a potential conflict of interest.

Copyright (c) $2019 \mathrm{Li}, \mathrm{Li}$ and $\mathrm{Li}$. This is an open-access article distributed under the terms of the Creative Commons Attribution License (CC BY). The use, distribution or reproduction in other forums is permitted, provided the original author(s) and the copyright owner(s) are credited and that the original publication in this journal is cited, in accordance with accepted academic practice. No use, distribution or reproduction is permitted which does not comply with these terms. 